\title{
ANALISIS TINGKAT KEPENTINGAN DAN KINERJA PELAYANAN KEDAI KOPI KETJE DAN LOKAL COFFEE DI KOTA METRO
}

\section{THE IMPORTANCE AND PERFORMANCE ANAL YSIS OF KETJE'S COFFEE AND LOKAL'S COFFEE SERVICES IN METRO CITY}

\author{
Agus Hudoyo, Tri Tarsita Aprilyano* \\ Universitas Lampung, JL. Prof. Dr. Soemantri Brojonegoro No. 1 Bandar Lampung 35145 \\ *Email: tri.tarsita15@gmail.com
}

(Diterima 22-08-2021; Disetujui 15-12-2021)

\begin{abstract}
ABSTRAK
Peningkatan yang pesat jumlah kedai kopi menyebabkan persaingan semakin ketat. Untuk dapat bertahan, kedai kopi perlu memberikan pelayanan yang terbaik agar pelanggannya puas apabila kinerja atribut pelayanan yang dinilai penting sesuai dengan harapan pelanggannya. Penelitian ini bertujuan untuk mengidentifikasi atribut-atribut pelayanan kedai kopi berdasarkan kepentingan dan kinerjanya serta menganalisis atribut-atribut pelayanan yang perlu dipertahankan dan ditingkatkan kinerjanya. Ada dua kedai kopi yang diteliti, yakni Kopi Ketje (KK) dan Lokal Coffee (LC) yang berlokasi di Kota Metro, Provinsi Lampung. Pengumpulan data dilakukan pada Agustus-September 2020. Sampel untuk tiap kedai sebanyak 35 responden dengan jumlah seluruh sampel sebanyak 70 responden. Teknik pengambilan sampel dilakukan secara bertahap. Hari dan waktu wawancara ditetapkan secara sengaja. Selanjutnya, sampel dipilih secara acak berdasarkan nomor meja. Atribut kepentingan dan kinerja diukur dalam skala likert dengan bantuan kuesioner. Kuesioner dengan 25 Atribut Kepentingan dan Kepuasan telah valid dan reliabel. Data dianalisis dengan metode Importance Performance Analysis (IPA). Hasil penelitian menunjukkan bahwa terdapat 15 atribut di KK dan 13 atribut di LC yang dinilai penting oleh responden. Selanjutnya, hasil studi ini menunjukkan bahwa terdapat 9 atribut di KK dan 7 atribut di LC yang dinilai memuaskan. Atribut yang perlu dipertahankan kinerjanya terdapat 9 atribut di KK dan 7 atribut di LC. Selanjutnya, atribut yang perlu ditingkatkan kinerjanya terdapat 6 atribut pada masing-masing kedai.
\end{abstract}

Kata kunci : Kedai Kopi, Atribut Pelayanan, Kepentingan, Kinerja

\begin{abstract}
The increased number of coffee shops has led to increasingly fierce competition. A coffee shop needs to provide the best service so customers are satisfied if the performance of service attributes are considered important according to customer expectations. This study aimed to identify service attributes of coffee shops based on their importance and performance and analyze service attributes need to be maintained and improved their performance. There were two coffee shops studied, Kopi Ketje (KK) and Local Coffee (LC) were located in Metro City, Lampung Province. Data collection was carried out in August-September 2020. The number of samples for each shop was 35 respondents with total sample was 70 respondents. The sampling technique was carried out in stages. The day and time of interview was set intentionally. A sample was selected randomly based on table numbers. Attributes of importance and performance were measured on a likert scale using questionnaire. The questionnaire with 25 Attribute of importance and satisfaction has been valid and reliable. Data were analyzed using Importance Performance Analysis (IPA) method. The results showed there were 15 attributes in KK and 13 attributes in LC which considered important by respondents. The results of this study indicated 9 attributes in KK and 7 attributes in LC which are considered satisfactory. Attributes that need to be maintained were 9 attributes in KK and 7 attributes in LC. Performance attributes that need to be improved were 6 attributes in each shop.
\end{abstract}

Keyword : Coffee Shop, Service Attributes, Importance, Performance 


\section{PENDAHULUAN}

Kopi merupakan salah satu
komoditas hasil perkebunan yang
digemari oleh masyarakat karena kopi
memiliki cita rasa dan aroma yang khas
sehingga konsumsi kopi mengalami
peningkatan. Menurut Kementerian Pertanian Republik Indonesia (2019), konsumsi kopi di Indonesia pada 2017 sebesar 0,276 juta ton/tahun atau 1,04 $\mathrm{kg} / \mathrm{kap} / \mathrm{tahun}$, dan pada 2018 sebesar 0,281 juta ton/tahun atau 1,05 $\mathrm{kg} / \mathrm{kap} /$ tahun. Menurut Toffin Indonesia (2020), konsumsi kopi di Indonesia pada 2019 sebesar 0,294 juta ton/tahun atau $1,10 \mathrm{~kg} / \mathrm{kap} /$ tahun. Hal ini menunjukkan bahwa konsumsi kopi di Indonesia mengalami peningkatan seiring dengan bertambahnya jumlah penduduk Indonesia tiap tahunnya.

Peningkatan jumlah konsumsi kopi di Indonesia membuat usaha berbasis kopi memiliki peluang yang baik salah satunya adalah kedai kopi. Kedai kopi merupakan tempat yang memberikan layanan penyediaan produk makanan dan minuman khususnya kopi. Menurut Toffin Indonesia (2020), jumlah kedai kopi di Indonesia pada 2019 mengalami peningkatan yang cukup signifikan yang dibandingkan dengan jumlah kedai kopi pada 2016 yaitu dari berjumlah sekitar
1.000 kedai pada 2016 meningkat menjadi lebih dari 2.950 kedai pada Agustus 2019, hal ini menunjukkan pertumbuhan kedai kopi di Indonesia yang semakin pesat yang mengakibatkan persaingan antar kedai kopi semakin ketat.

Persaingan yang semakin ketat juga dirasakan kedai kopi yang ada di Kota Metro. Menurut Dinas Perdagangan Kota Metro (2020), kedai kopi yang ada idi Kota iMetro iberjumlah i41 kedai kopi. Dari 41ikedai ikopi iyang iterdapat di Kota iMetro iterdapat idua ikedai ikopi yang imenarik untuk iditeliti yaitu iKopi Ketje dan iLokal iCoffee. Kopi iKetje dan iLokal Coffee imerupakan ikedai kopi iasal Lampung yang ikeduanya sudah iberdiri sejak 2017.iKedai iKopi Ketje idi iLampung berpusat idi iBandar Lampung idan idi Lampung isendiri telah memiliki ibeberapa cabang idan itiga franchise iyang isalah satunya iterdapat di iKota iMetro, isedangkan Lokal Coffee merupakan ikedai ikopi iyang hanya terdapat idi iKota iMetro. Kedua kedai kopi itersebut imenawarkan iberbagai menu yang iberagam idan ijuga menawarkan berbagai ifasilitas iseperti hiburan imusik, wifi, idan ifasilitas lainnya. 
Agar iusaha ikedai ikopi idapat bertahan, pengusaha ikedai ikopi iharus memiliki strategi iyang ibaik isalah satunya iyaitu dengan imemberikan atribut ipelayanan iyang terbaik iagar memuaskan konsumen. Menurut Warokka et al (2017), iatribut pelayanan yang ipada itiap ikedai ikopi iciri khas yang iberbeda imenjadi isalah isatu idaya tarik ibagi ikonsumen. Konsumen terkadang bingung imemilih ikedai ikopi mana iyang akan idikunjungi ikarena semua ikedai ikopi yang iada ihampir sama. Yang imembuat kedai ikopi berbeda idengan iyang ilainnya adalah pelayanan iyang idiberikan. Atribut pelayanan iyang idiberikan imemiliki pengaruh iyang ibesar idalam ikepuasan konsumen.

Pengusaha ikedai ikopi ijuga iperlu melakukan penilaian iterhadap ikedai kopinya iseperti penilaian iterhadap pelayanan iyang diberikan ke konsumen. Dalam imelakukan ipenilaian tersebut dapat dilakukan dengan bertanya langsung ke konsumen atau mengizinkan peneliti iuntuk imeneliti idi kedainya. Hasil dari penelitianitersebut dapat dijadikan sebagai igambaran kedai ikopi menurut konsumennya dan sebagai bahan pertimbangan dalam menentukan pelayanan apa iyang iperlu dipertahankan dan ditingkatkan iagar iusaha ikedai ikopi dapat lebih ibaik idan imemenuhi kepuasan konsumen.

Tingkat kepuasan merupakan hasil kerja yang dirasakan oleh konsumen yang mengalami ikinerja yang dilakukan ioleh suatu iusaha iyang dibandingkan idengan harapannya. Salah satu cara untuk meningkatkan kepuasan konsumen adalah dengan imeningkatkan kinerja atribut pelayanan agar dapat memuaskan konsumen. Dengan memuaskan konsumen bisa saja konsumen yang merasa puas dapat menjadi pelanggan tetap dan dapat menarik lebih ibanyak konsumen untuk melakukan pembelian (Lubis et al., 2020);(Damanik, 2014).

Berdasarkan iuraian idi atas, penelitian ipada Kedai iKopi iKetje idan Lokal iCoffee iMetro memiliki itujuan yaitu imengidentifikasi kepentingan atribut pelayanan, mengidentifikasi kinerja iatribut ipelayanan, dan menganalisis iatribut ipelayanan iyang perlu idipertahankan idan iditingkatkan kinerjanya.

\section{METODE IPENELITIAN}

Penelitian iini idilakukan idi iKopi Ketje idan Lokal iCoffee iMetro idengan metode survey. Penentuan lokasi penelitian dilakukan secara sengaja 


\section{ANALISIS TINGKAT KEPENTINGAN DAN KINERJA PELAYANAN \\ KEDAI KOPI KETJE DAN LOKAL COFFEE DI KOTA METRO \\ Agus Hudoyo, Tri Tarsita Aprilyano}

(purposive) idengan ipertimbangan kedua lokasi ipenelitian imemiliki idaya itarik tersendiri. Kopi Ketje menggunakan base kopi Lampung dan memberikan beberapa fasilitas iyang imenghibur konsumen seperti tv, wifi, dan live music yang diadakan setiap tiga kali dalam satu minggu.iUntuk Lokal Coffee, kedai ikopi ini memiliki tempat yang nyaman dan memiliki beberapa spot untuk berfoto dan Lokal Coffee hanya ada di Kota Metro. Kedai Kopi Ketje dan Lokal Coffee termasuk dalam satu unit analisis, sehingga keragaan atribut dari kedua kedai kopi ini dapat dibandingkan. Jumlah sampel pada penelitian ini berjumlah 70 responden dengan 35 responden pada setiap kedai kopi. Pengambilan sampel dilakukan secara bertahap dengan mengundi inomor imeja yang dilakukan pada 25 meja untuk Kopi Ketje dan 20 meja untuk Lokal iCoffee. Penelitian ini dilakukan selama dua minggu per kedai kopi yang dibagi ke dalam empat hari per minggu. Penelitian telah dilakukan pada bulan Agustus sampaiiSeptember 2020.

Metode ianalisis iyang idigunakan untuk menjawab itujuan ipertama isampai tujuan ketiga iyaitu iatribut ipelayanan yang idinilai penting ioleh ikonsumen, kinerja idari iatribut pelayanan iyang diberikan, dan atribut pelayanan yang perlu untuk dipertahankan dan ditingkatkan kinerjanya. Atribut iyang digunakan mengacu pada penelitian terdahulu dan berdasarkan pengamatan di lokasi yang digunakan pada penelitian ini dapat dilihat pada Tabel 1.

Tabeli1.IAtribut IKepentingan Idan IKinerja Iyang Diidentifikasi

\begin{tabular}{ll}
\hline Variabel & Atribut \\
\hline Produk & Cita irasa i \\
& Harga \\
& Ukuran tiapiporsi \\
& Keberagaman menu \\
& Kesesuaian produk \\
& Penampilan produk \\
\hline Perhatian & Kebersihan tempat \\
& Penampilan karyawan \\
& Keramahan dan kesopanan karyawan \\
& Keadilan dalam pelayanan \\
& Kecepatan dan ketelitian pelayanan \\
& Kepedulian terhadap pelanggan \\
& Kemudahan dalam pembayaran \\
& Ketanggapan terhadap kritik dan isaran \\
& Kemampuan dalam berkomunikasi \\
& Pengetahuan terhadap produk \\
& Keamanan \\
\hline Fasilitas & Lokasi yang nyaman \\
& Ketersediaan wifi \\
& Ketersediaan tempat iparkir \\
& Ketersediaan toilet \\
& Ketersediaan mushola \\
& Ketersediaan penyejuk ruangan \\
& Kapasitas meja dan kursi \\
& Ketersediaan hiburan \\
&
\end{tabular}

Atribut-atribut tersebut akan dicantumkan pada daftar pertanyaan dalam ikuesioner yang idinilai idengan menggunakan iskala likert iyang didalamnya terdapat lima alternatif jawaban idalam ibentuk iskor idari sangat tidak ipuas iatau isangat itidak ipenting dengan iskor il isampai idengan isangat 
puas atau isangat ipenting idengan iskor 5. Sebelum idigunakan, iatribut itersebut akan diuji ivaliditas idan ireliabilitasnya. Pengujian dilakukan idengan itujuan yaitu iuntuk mengetahui iapakah pertanyaan idalam kuesioner itelah ivalid dan ireliabel, isehingga pertanyaan idapat digunakan iuntuk mengukur iatribut pelayanan iyang iada.

Uji ivaliditas imerupakan pengujian yang dilakukan iuntuk imengetahui ialat ukur iyang digunakan itelah isesuai idan mampu mengukur isesuatu iyang iingin diukur. Pada penelitian iini iperhitungan validitas menggunakan ianalisis koefisien korelasi Product iMoment iPearson. Perhitungan dilakukan idengan icara mengkorelasikan antara iskor iatribut pelayanan idengan iskor total atribut.iDari ihasil iperhitungan ikorelasi akan idiperoleh isuatu ikoefisien ikorelasi untuk imengukur iuntuk imenentukan apakah suatu iatribut itersebut ilayak digunakan iatau tidak.

Dalam ipenentuan ilayak iatau tidaknya isuatu item iyang iakan digunakan, idilakukan iuji signifikansi koefisien ikorelasi ipada itaraf signifikansi i0,05. Terdapat kriteria pengujian sebagai iberikut.

a) Jika ir ihitung $\mathrm{i} \geq \mathrm{i}$ critical ivalue $\mathrm{i}(\mathrm{r}$ tabel) (uji i2 isisi idengan isig. i0,05), maka instrumen iatau iitem-item pertanyaan berkorelasi isignifikan terhadap iskor itotal (dinyatakan ivalid).

b) Jika ir ihitung $\mathrm{i}<\mathrm{i}$ critical ivalue $\mathrm{i}(\mathrm{r}$ tabel) (uji i2 isisi idengan isig. i0,05), maka instrumen iatau iitem-item pertanyaan itidak berkorelasi isignifikan terhadap iskor itotal (dinyatakan itidak valid) (Azwar, 2007).

Uji ivaliditas itelah idilakukan pada Juli 2020 yang idilakukan ipada i30 responden idi iKopi Ketje idan iLokal Coffee iMetro. Nilai signifikan iyang digunakan i5\% idengan ir tabel iyang digunakan isebesar i0,361. Berdasarkan hasil iuji ivaliditas idapat disimpulkan bahwa i25 iatribut iyang digunakan itelah valid ikarena inilai $\mathrm{i}>$ ir tabel yang berarti atribut iyang idigunakan idapat mengukur kepentingan idan ikinerja idari kedai kopi.

Setelah iatribut idinyatakan ivalid selanjutnya dilakukan iuji ireliabilitas. Uji ireliabilitas merupakan ipengujian yang idilakukan iuntuk mengetahui sejauh imana ihasil ipengukuran dengan kuesioner itidak iberubah iatau konsisten sehingga idapat idiandalkan. Semua atribut yang sudah ivalid iakan digunakan pada iuji ireliabel iini. Untuk mencari 


\section{ANALISIS TINGKAT KEPENTINGAN DAN KINERJA PELAYANAN \\ KEDAI KOPI KETJE DAN LOKAL COFFEE DI KOTA METRO \\ Agus Hudoyo, Tri Tarsita Aprilyano}

reliabilitas idalam ipenelitian iini perhitungan dipilih dengan menggunakan rumus varian alpha.

Menurut Sugiyono (2009), reliabilitas Croanbach's Alpha idiukur berdasarkan skala alpha i0 sampai dengan 1, nilai tingkat kehandalan Croanbach's iAlpha yaitu i0,70. Apabila nilai iCroanbach's iAlpha i> icritical value, imaka ikuesioner idinyatakan reliabel, sebaliknya apabila inilai Croanbach's iAlpha kurang dari i0,70 maka inilai ikehandalannya rendah.

Uji ireliabilitas itelah idilakukan pada iJuli 2020 iyang idilakukan ipada 30 responden idi Kopi iKetje idan iLokal Coffee iMetro. Berdasarkan ihasil iuji reliabilitas idapat disimpulkan ibahwa atribut iyang idigunakan telah ireliabel karena inilai iyang ididapatkan yaitu 0,752 iuntuk ikepentingan idan i0,751 untuk ikinerja, idimana inilai ikeduanya lebih dari i0,70 iyang iberarti iatribut dapat diandalkan.

Atribut ikepentingan idan ikinerja yang itelah diidentifikasi idan itelah dinyatakan ivalid dan reliabel dapat digunakan dalam kuesioner dan selanjutnya akan idilakukan pengambilan data idengan mewawancarai responden yang merupakan konsumen pada kedai kopi yang iakan iditeliti dengan ibantuan kuesioner. Setelah data terkumpul selanjutnya akan dianalisis tingkat kesesuaian dan metode Importance Performance iAnalysis (IPA).

Tingkat kesesuaian merupakan hasil dari perbandingan kesesuaian antara kinerja dan kepentingan pada setiap atribut. Fungsi tingkat kesesuaian dihitung untuk mengetahui tingkat kinerja iyang idiberikan sudah sesuai atau belum idengan kepentingan dari tiap atribut. Supranto (2006) mengungkapkan tingkat ikesesuaian memiliki beberapa kriteria yaitu jika skor lebih dari 100 persen kinerja yang diberikan dinilai sangat sesuai dengan harapan dan melebihi apa yang dianggap penting ioleh responden, jika skor sama dengan 100 persen kinerja yang diberikan dinilai sesuai dengan harapan dan memenuhi apa yang dianggap penting oleh responden, jika kurang dari 100 persen kinerja dinilai kurang isesuai dengan harapan dan tidak memenuhi apa yang dianggap penting oleh responden.

Menurut Supranto (2006), imetode IPA merupakan ialat ianalisis iyang menggambarkan ikinerja idari isebuah produk dan ijasa idibandingkan idengan harapan iatau tingkat ikepentingan idan kinerja iyang digambarkan idengan bentuk idiagram kartesius. Supranto 
(2006), mendefinisikan diagram kartesius sebagai isuatu ibangun yang memiliki empat ibagian iyang idisebut kuadran. Diagram kartesius memiliki titik koordinat berupa kombinasi dari sumbu $\mathrm{Y}$ yang menggambarkan kepentingan (Importance)idan sumbu $\mathrm{X}$ menggambarkan kinerja (Performance) dari ipelayanan iyang diberikan.iDiagram kartesius idibagi ikedalam empat kuadran dimana tiap ikuadran imemiliki fungsinya masing-masing yaitu kuadran I (prioritas utama), kuadran II (perlu dipertahankan), kuadran iIII i(prioritas rendah), dan kuadran IV (berlebihan).

\section{HASIL IDAN IPEMBAHASAN Karakteristik iResponden}

Karakteristik responden dibedakan berdasarkan ijenis ikelamin, iusia, tingkat pendidikan iterakhir, ipekerjaan, idaerah asal, dan ifrekuensi ikunjungan isebelum pandemi Covid-19 idan isetelah iadanya pandemi Covid-19. Responden iyang mengunjungi Kopi Ketje didominasi oleh jenis kelamin laki-laki, sedangkan Lokal Coffee didominasi oleh jenis kelamin perempuan.

Lokal Coffee didominasi oleh jenis kelamin perempuan dikarenakan Lokal Coffee memberikan suasana kedai kopi yang cocok untuk berfoto, selain iitu juga Lokal Coffee memiliki menu minuman kopi dan non-kopi dan dessert yang disukai oleh perempuan.iResponden yang mengunjungi Kopi iKetje idan iLokal Coffee ididominasi oleh irentang iusia 21-30 itahun ipada masing-masing ikedai kopi.iHal iini idikarenakan rentang iusia 21-30 merupakan usia yang aktif berkegiatan ioleh isebab iitu ikedai ikopi dapat imenjadi ialternatif itempat idalam berkegiatan.iSebagian besar responden memiliki tingkat ipendidikan iterakhir SMA/SMK idikarenakan ilokasi idari kedua kedai ikopi iyang idekat idengan sekolah dan kampus. Pekerjaan konsumen iKopi iKetje dan iLokal Coffee didominasi oleh kelompok pelajar/mahasiswa. Hal iini dikarenakan lokasi idari ikedua ikedai ikopi yang dekat idengan isekolah idan ikampus dan juga ipelajar/mahasiswa iyang ibelajar secara online iyang imemanfaatkan iwifi yang iada di kedai ikopi iuntuk melakukan ikegiatan tersebut. Responden yang mengunjungi Kopi Ketje didominasi ioleh imasyarakat idi idalam Kota iMetro, isedangkan iLokal iCoffee didominasi ioleh imasyarakat iluar iKota Metro. Hal tersebut dikarenakan lokasi Lokal Coffee yang lebih strategis dibandingkan dengan Kopi Ketje.iFrekuensi kunjungan isebelum pandemi Covid-19 dalam sebulan 
mayoritas iresponden mengunjungi iKopi

Ketje isebanyak isatu kali, sedangkan responden mayoritas imengunjungi Lokal Coffee isebanyak idua ikali. Setelah adanya ipandemi iCovid-19 iresponden mayoritas imengunjungi iKopi iKetje tetap sebanyak isatu ikali, isedangkan responden yang imengunjungi Lokal Coffee imeningkat menjadi ilebih idari tiga ikali. Frekuensi kunjungan responden Lokal Coffee mengalami peningkatan dari sebelum adanya pandemi dan setelah adanya pandemi, hal tersebut dikarenakan setelah adanya pandemi iterdapat ibanyak kegiatan yang dilakukan isecara ionline seperti kegiatan belajar mengajar dan bekerja, sehingga responden memerlukan akses internet sehigga memanfaatkan fasilitas wifi yang ada di kedai kopi.

\section{Kepentingan, Kinerja, dan Tingkat} KesesuaianAtribut-Atribut Kopi Ketje dan Lokal Coffee

Kelompok iatribut iproduk iyang terdapat pada ipenelitian iini iterdapat i6 atribut. iTabel 2 imenunjukkan ibahwa atribut ipada kelompok iatribut iproduk dinilai ipenting oleh ikonsumen ipada kedua ikedai ikopi. Hal ini ditandai dengan perolehan rata-rata kepentingan atribut yang telah imelampaui skor empat pada kedua kedai ikopi. Atribut cita rasa merupakan atribut dengan nilai tertinggi pada kedua kedai kopi.iSkor rata-rata kinerja pada kedua kedai kopi menunjukkan iatribut ipada kelompok atribut produk telah memuaskan konsumen, kecuali atribut harga dan ukuran tiap porsi pada kedua kedai kopi dan atribut penampilan produk pada Lokal Coffee. Hal iini disebabkan ioleh skor rata-rata pada ketiga atribut itersebut belum mencapai iempat. Atribut yang memiliki skor tertinggi adalah cita rasa pada Kopi Ketje dan pada Lokal Coffee yaitu atribut keberagaman menu dan kesesuaian iproduk. Tingkat kesesuaian seluruh atribut di kedua kedai kopi pada kelompok atribut ini belum mencapai 100 persen, artinya kinerja seluruh atribut yang diberikan dinilai kurang sesuai dengan harapan dan belum memenuhi apa yang dianggap penting oleh konsumen.

Kelompok iatribut iperhatian iyang terdapat pada ipenelitian iini iterdapat i11 atribut. Tabel i2 imenunjukkan iseluruh atribut ipada kedua ikedai ikopi idalam kelompok iatribut perhatian idinilai penting ioleh ikonsumen, kecuali iatribut penampilan ikaryawan ipada Lokal Coffee. Hal iini idisebabkan ioleh iskor rata-rata iatribut ipenampilan ikaryawan pada Lokal iCoffee itidak imencapai empat, iberarti atribut iini idianggap 
kurang ipenting ioleh konsumen. Atribut kebersihan itempat merupakan iatribut dengan iskor itertinggi pada ikedua ikedai kopi. Hal iini menunjukkan bahwa konsumen mementingkan ikebersihan tempat idalam memilih ikedai ikopi iyang akan idikunjungi. Kinerja iatribut idi kedua ikedai ikopi ipada kelompok atribut iini itelah imemuaskan konsumen, kecuali iketanggapan iterhadap kritik dan saran idan ikemampuan berkomunikasi pada iKopi iKetje idan ipada Lokal Coffee iyaitu ikebersihan itempat, keramahan idan ikesopanan ikaryawan, keadilan idalam ipelayanan, ikecepatan dan ketelitian idalam ipelayanan, idan kepedulian terhadap ipelanggan. Atributatribut itersebut dinilai ibelum memuaskan ikonsumen. Tingkat kesesuaian iseluruh iatribut ipada kedua kedai ikopi ibelum imencapai 1100 persen, ikecuali idua iatribut ipada iLokal Coffee iyaitu ikemudahan idalam pembayaran dan iketanggapan iterhadap kritik idan isaran. Hal iini imenunjukkan bahwa iatribut iyang terdapat ipada kelompok iini ikurang isesuai dengan harapan idan ibelum imemenuhi iapa yang idianggap ipenting, ikecuali idua atribut pada iLokal iCoffee iyaitu kemudahan pembayaran idan ketanggapan iterhadap kritik dan isaran yang idinilai itelah isesuai idengan harapan idan itelah imemenuhi iapa iyang dianggap ipenting ioleh ikonsumen.

Kelompok iatribut ifasilitas iyang terdapat pada ipenelitian iini iterdapat i8 atribut. Skor rata-rata ikepentingan seluruh iatribut ipada kedua ikedai ikopi dinilai ipenting ioleh responden ikecuali atribut iketersediaan hiburan.iHal iini disebabkan ioleh iskor irata-rata iatribut ketersediaan ihiburan itidak mencapai empat, iberarti iatribut iini dianggap kurang ipenting ioleh ikonsumen. I

Atribut dengan iskor irata-rata tertinggi pada ikedua kedai ikopi diperoleh atribut kenyamanan lokasi. Tabel i2 menunjukkan ibahwa kinerja dari iatribut pada ikelompok iatribut iini belum mencapai iskor iempat iyang berarti atribut ikurang imemuaskan konsumen, kecuali iatribut ikenyamanan lokasi idan ketersediaan iwifi ipada iKopi Ketje idan atribut iketersediaan itoilet dan kapasitas meja idan ikursi ipada iLokal Coffee. Hal ini menandakan ibahwa kinerja idari atribut pada kelompok iini masih terbilang isedikit rendah karena kebanyakan iatribut ipada ikelompok ini belum imencapai iskor iempat. i iTingkat kesesuaian iseluruh iatribut ipada ikedua kedai kopi ibelum imencapai i100 persen, kecuali atribut iketersediaan ihiburan. Hal 


\section{ANALISIS TINGKAT KEPENTINGAN DAN KINERJA PELAYANAN \\ KEDAI KOPI KETJE DAN LOKAL COFFEE DI KOTA METRO \\ Agus Hudoyo, Tri Tarsita Aprilyano}

ini menunjukkan ibahwa iatribut iyang terdapat pada ikelompok iini ikurang sesuai idengan harapan idan ibelum memenuhi iapa iyang dianggap ipenting oleh ikonsumen, ikecuali atribut ketersediaan ihiburan iyang idinilai telah sesuai idengan iharapan ikonsumen idan telah imemenuhi iapa iyang idianggap penting oleh ikonsumen.

Tabel i2. i iRata-rata itingkat ikepentingan, itingkat ikinerja, idan itingkat ikesesuaian iKopi iKetje idan iLokal iCoffee iKota iMetro

\begin{tabular}{|c|c|c|c|c|c|c|c|}
\hline \multirow{2}{*}{$\begin{array}{c}\text { Kelompok } \\
\text { Atribut }\end{array}$} & \multirow[b]{2}{*}{ Atribut } & \multicolumn{3}{|c|}{ Kopi iKetje } & \multicolumn{3}{|c|}{ Lokal iCoffee } \\
\hline & & $\begin{array}{l}\text { Kepen- } \\
\text { tingan }\end{array}$ & Kinerja & $\begin{array}{l}\text { Kese- } \\
\text { suaian }\end{array}$ & $\begin{array}{l}\text { Kepen- } \\
\text { tingan }\end{array}$ & Kinerja & $\begin{array}{l}\text { Kese- } \\
\text { suaian }\end{array}$ \\
\hline \multirow[t]{6}{*}{ Produk } & Cita iRasa i & 4,77 & 4,17 & 87,43 & 4,8 & 3,97 & 82,74 \\
\hline & Harga & 4,46 & 3,94 & 88,46 & 4,46 & 3,83 & 85,90 \\
\hline & Ukuran Tiap Porsi & 4,23 & 3,83 & 90,54 & 4,4 & 3,57 & 81,17 \\
\hline & Keberagaman Menu & 4,32 & 4 & 92,72 & 4,51 & 4,06 & 89,87 \\
\hline & Kesesuaian Produk & 4,54 & 4,09 & 89,94 & 4,51 & 4,06 & 89,87 \\
\hline & Penampilan Produk & 4,34 & 4,14 & 95,40 & 4,29 & 3,89 & 90,67 \\
\hline \multirow[t]{12}{*}{ Perhatian } & Kebersihan Tempat & 4,63 & 4,37 & 94,44 & 4,77 & 3,94 & 82,64 \\
\hline & PenampilaniKaryawan & 4,2 & 4,09 & 97,28 & 3,94 & 3,8 & 96,38 \\
\hline & Keramahan dan & 4,6 & 4,23 & 91,93 & 4,74 & 3,94 & 83,13 \\
\hline & Kesopanan Karyawan & & & & & & \\
\hline & Keadilan Pelayanan & 4,43 & 4,2 & 94,84 & 4,54 & 3,83 & 84,28 \\
\hline & $\begin{array}{l}\text { Kecepatan dan Ketelitian } \\
\text { Pelayanan }\end{array}$ & 4,43 & 4 & 90,32 & 4,57 & 3,91 & 85,63 \\
\hline & $\begin{array}{l}\text { Kepedulian Terhadap } \\
\text { Pelanggan }\end{array}$ & 4,46 & 4,14 & 92,95 & 4,26 & 3,91 & 91,95 \\
\hline & $\begin{array}{l}\text { Kemudahan Dalam } \\
\text { Pembayaran }\end{array}$ & 4,49 & 4,29 & 95,54 & 4 & 4,09 & 102,14 \\
\hline & $\begin{array}{l}\text { Ketanggapan Terhadap } \\
\text { Kritik dan Saran }\end{array}$ & 4,17 & 3,94 & 94,52 & 3,97 & 3,97 & 100 \\
\hline & $\begin{array}{l}\text { Kemampuan } \\
\text { Berkomunikasi }\end{array}$ & 4,4 & 3,94 & 89,61 & 4,11 & 3,97 & 96,53 \\
\hline & $\begin{array}{l}\text { Pengetahuan Terhadap } \\
\text { Produk }\end{array}$ & 4,34 & 4 & 92,11 & 4,34 & 4,09 & 94,08 \\
\hline & Keamanan & 4,6 & 4,14 & 90,06 & 4,29 & 4 & 93,33 \\
\hline \multirow[t]{9}{*}{ Fasilitas } & Kenyamanan Lokasi & 4,66 & 4,06 & 87,12 & 4,6 & 3,86 & 83,85 \\
\hline & Ketersediaan Wifi & 4,31 & 4 & 92,72 & 4,26 & 3,83 & 89,93 \\
\hline & Tempat iParkir & 4,43 & 3,94 & 89,03 & 4,49 & 3,89 & 86,62 \\
\hline & Ketersediaan Toilet & 4,63 & 3,91 & 84,57 & 4,57 & 4,03 & 88,13 \\
\hline & Ketersediaan Mushola & 4,49 & 3,89 & 86,62 & 4,4 & 3,74 & 85,07 \\
\hline & PenyejukiRuangan & 4,09 & 3,77 & 92,31 & 4,31 & 3,86 & 89,40 \\
\hline & $\begin{array}{l}\text { Kapasitas Mejaidan } \\
\text { Kursi }\end{array}$ & 4,11 & 3,91 & 95,14 & 4,34 & 3,97 & 91,45 \\
\hline & Ketersediaan Hiburan & 3,54 & 3,77 & 106,45 & 3,71 & 3,8 & 102,31 \\
\hline & Rata-rata & 4,39 & 4,03 & 92,08 & 4,37 & 3,91 & 89,88 \\
\hline
\end{tabular}

Importance Performance Analysis (IPA)

Metode iIPA imerupakan imetode yang digunakan iuntuk imenggambarkan atau mengetahui itingkat ikepentingan dan ikinerja dari itiap iatribut iyang itelah ditentukan dengan idiagram ikartesius. 
Pada iTabel i2 terdapat idata inilai rata-rata idari itingkat kepentingan idan tingkat ikinerja iatribut pada Kopi iKetje dan Lokal Coffee. Nilai rata-rata tersebut selanjutnya diolah dan dipetakan ke dalam diagram kartesius dari metode IPA. Diagram kartesius pada Kopi Ketje dan Lokal Coffee dapat idilihat ipada Gambar 2.

Kopi iKetje

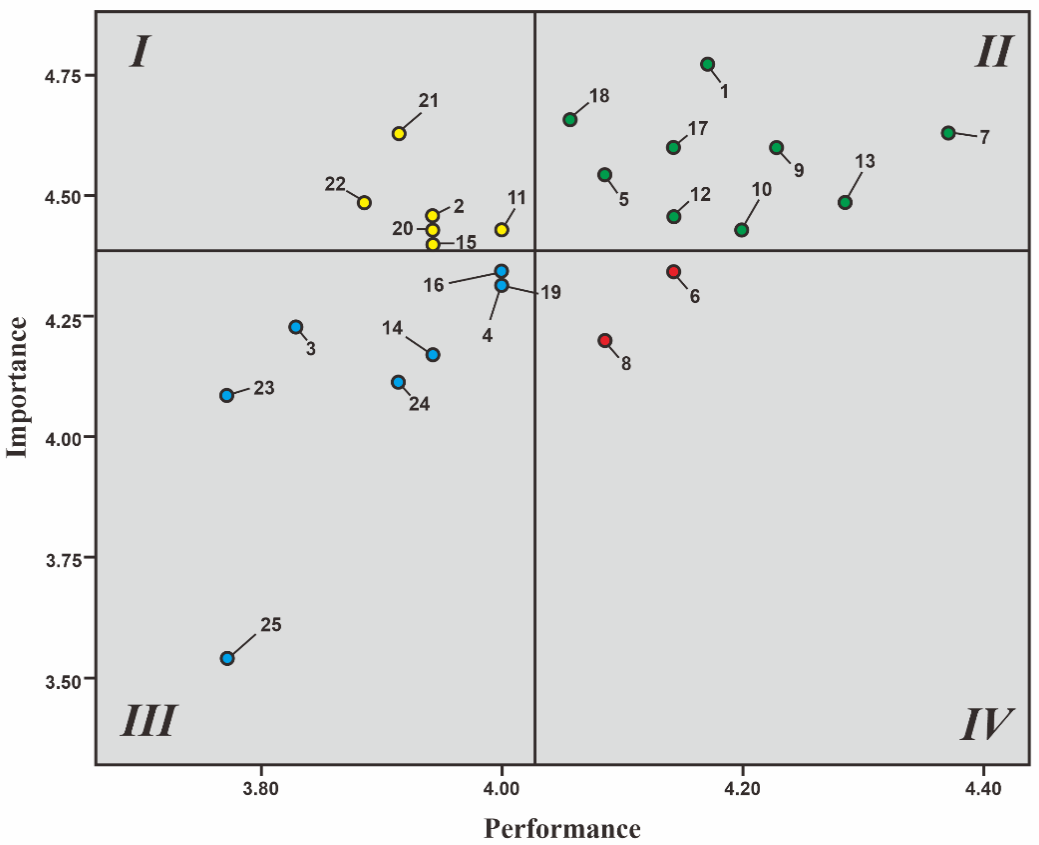

Lokal iCoffee

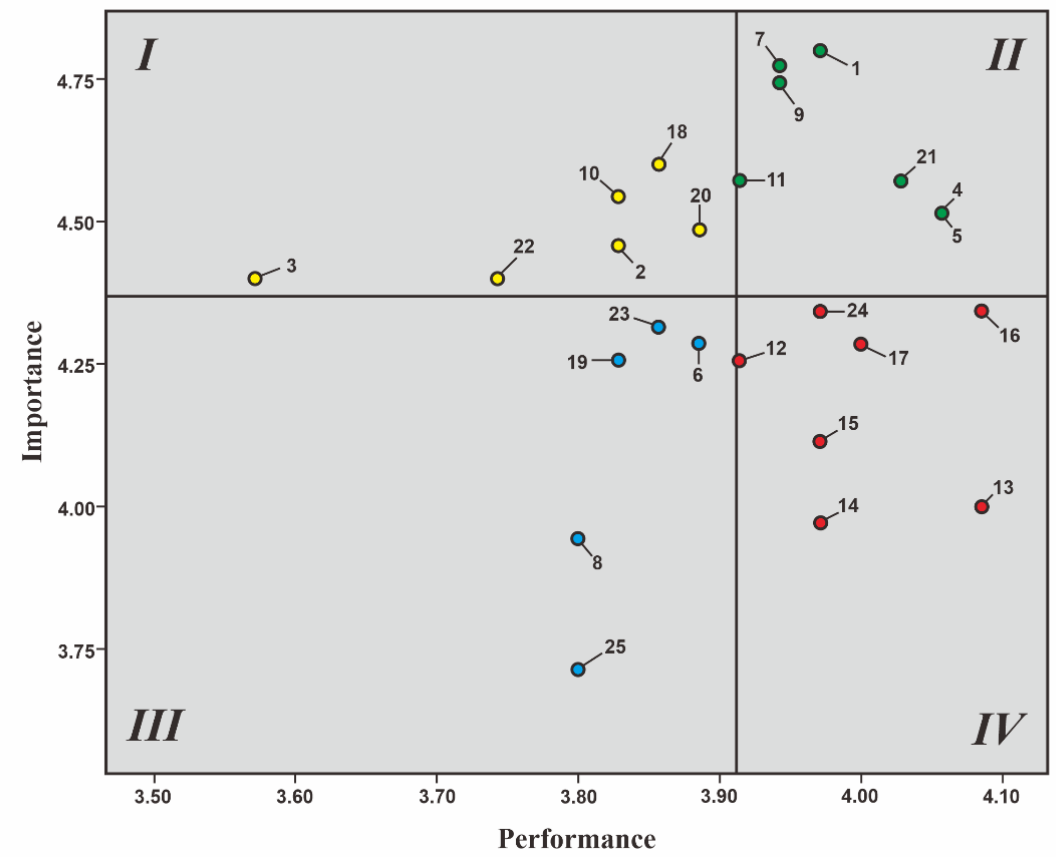

Gambari1. Diagram Kartesius Kopi Ketje dan Lokal iCoffee 
Kuadran iI imenunjukkan iatribut pelayanan yang idiberikan idianggap penting iuntuk mempengaruhi ikepuasan konsumen, inamun pihak ikedai ikopi belum imelaksanakan sesuai ikeinginan konsumen, isehingga iperlu untuk ditigkatkan ikualitas ipelayanannya agar lebih imemuaskan ikonsumen. Atribut pada iKopi iKetje iyang itermasuk kedalam kuadran iI iyaitu iharga, kecepatan idan ketelitian pelayanan, kemampuan berkomunikasi, itempat parkir, itoilet, idan mushola. Atribut idi Lokal iCoffee iyang termasuk ikedalam kuadran iI iyaitu iharga, ukuran iporsi, keadilan ipelayanan, kenyamanan ilokasi, tempat iparkir, idan mushola.

Untuk iatribut ipada ikedua ilokasi penelitian yang imemiliki ikesamaan pada ikuadran iI adalah iharga, itempat parkir, idan imushola. Atribut itempat parkir idan imushola imasuk kedalam kuadran iI isesuai idengan ipenelitian Prasetyowati et al (2016) idan Putra (2019) Atribut iharga imasuk ikedalam kuadran iI sesuai iidengan ipenelitian Arfi (2015), Lieberto (2019) , idan Meilani et al (2019) dimana iketiga atribut itersebut idianggap penting namun kurang imemuaskan konsumen.

Kuadran iII imenunjukkan iatribut pelayanan yang idiberikan idianggap sangat ipenting dan telah idilaksanakan dengan ibaik, isehingga perlu iuntuk dipertahankan. Pada iKopi iKetje atribut yang itermasuk ikedalam ikuadran iini yaitu icita irasa, ikesesuaian iproduk yang diberikan idan iditawarkan, ikebersihan tempat, ikeramahan idan ikesopanan karyawan, ikeadilan ipelayanan, kepedulian terhadap ipelanggan, kemudahan pembayaran, ikeamanan, idan kenyamanan lokasi. Pada iLokal iCoffee atribut iyang termasuk ikedalam ikuadran ini iyaitu icita rasa, imenu iberagam, kesesuaian iproduk yang idiberikan idan ditawarkan, ikebersihan tempat, keramahan idan ikesopanan karyawan, kecepatan idan iketelitian pelayanan, idan toilet.

Untuk iatribut ipada ikedua ilokasi penelitian yang imemiliki ikesamaan pada ikuadran iII adalah iatribut icita rasa, ikesesuaian iproduk yang idiberikan dan iditawarkan, ikebersihan tempat, keramahan idan ikesopanan karyawan.iHal iini isesuai idengan penelitian, \Arfi (2015), Damanik (2014), Prasetyowati et al (2016), Triani et al (2016), Meilani et al (2019), Putra (2019), idan Lubis et al (2020) dimana atribut icita irasa iyang imasuk kedalam kuadran iII. 
Untuk iatribut kebersihan itempat dianggap ipenting idan termasuk kedalam kuadran iII isesuai dengan penelitian Prasetyowati et al (2016) idan Meilani et al (2019). Untuk iatribut ikeramahan dan kesopanan ikaryawan idianggap ipenting dan itermasuk ikedalam ikuadran iII sesuai dengan ipenelitian Arfi (2015) dan Prasetyowati et al (2016).

Kuadran iIII imenunjukkan iatribut pelayanan yang idiberikan idianggap kurang ipenting dan idilaksanakan ibiasabiasa isaja. i iPada Kopi iKetje iatribut yang itermasuk ikedalam kuadran iini yaitu iukuran iporsi, imenu iyang beragam, iketanggapan iterhadap ikritik dan saran, ipengetahuan ikaryawan terhadap produk, iwifi, ikapasitas imeja dan ikursi, penyejuk iruangan, idan hiburan. iPada iLokal Coffee iatribut pelayanan iyang itermasuk kedalam kuadran iini iyaitu ipenampilan produk, penampilan ikaryawan, iwifi, kapasitas meja idan ikursi, idan ihiburan. Atribut pada ikedua ilokasi ipenelitian iyang memiliki ikesamaan ipada ikuadran iini adalah wifi, ikapasitas imeja idan ikursi, dan hiburan.

Kuadran iIV imenunjukkan iatribut pelayanan yang idiberikan idianggap kurang ipenting oleh ikonsumen inamun dilakukan berlebihan, sehingga menimbulkan ipemborosan iakan tetapi memberikan ikepuasan ibagi konsumen. Pada iKopi iKetje iatribut pelayanan yang termasuk ikedalam ikuadran ini iyaitu penampilan iproduk idan penampilan karyawan.iPada iLokal iCoffee atribut pelayanan iyang itermasuk ikedalam kuadran iini iyaitu ikepedulian iterhadap pelanggan, kemudahan pembayaran, ketanggapan iterhadap ikritik idan isaran, kemampuan iberkomunikasi ikaryawan, pengetahuan ikaryawan iterhadap produk, keamanan, idan ipenyejuk iruangan.

Secara ikeseluruhan, ikedua ikedai ikopi telah berupaya iuntuk imemberikan pelayanan yang terbaik iuntuk memuaskan ikonsumennya, namun terdapat iatribut ipelayanan iyang perlu dipertahankan idan iditingkatkan. Atribut yang iperlu idipertahankan ikualitas pelayanannya iterdapat ipada ikuadran II. Atribut iyang iperlu iuntuk iditingkatkan kualitas ipelayanannya iberada ipada kuadran I, isehingga idapat ilebih memuaskan konsumen. Hal iini iberarti bahwa iatribut pelayanan imemiliki peran yang ipenting dalam imemuaskan konsumen.

\section{KESIMPULAN DAN SARAN}

\section{Kesimpulan}

Berdasarkan hasil penelitian terhadap tingkat kepentingan dan kinerja 
pelayanan Kedai Kopi Ketje dan Lokal Coffee di Kota Metro, maka dapat disimpulkan :

1. a. Atribut pelayanan yang dinilai penting oleh kosumen Kopi Ketje terdapat 15 atribut yaitu cita rasa, harga, kesesuaian produk, kebersihan tempat, keramahan dan kesopanan karyawan, keadilan pelayanan, kecepatan dan ketelitian dalam pelayanan, kepedulian terhadap pelanggan, keamanan, kemudahan pembayaran, kemampuan berkomunikasi, kenyamanan lokasi, ketersediaan tempat parkir, ketersediaan toilet, dan ketersediaan mushola.

b. Atribut pelayanan yang dinilai penting oleh konsumen Lokal Coffee terdapat 13 atribut yaitu cita rasa, harga, ukuran porsi, menu beragam, kesesuaian produk, kebersihan tempat, keramahan dan kesopanan karyawan, keadilan dalam pelayanan, kecepatan dan ketelitian dalam pelayanan, kenyamanan lokasi, ketersediaan tempat parkir, ketersediaan toilet, dan ketersediaan mushola.
2. a. Atribut pelayanan yang dinilai dapat memuaskan konsumen Kopi Ketje terdapat 9 atribut yaitu cita rasa, kesesuaian produk, kebersihan tempat, keramahan dan kesopanan karyawan, keadilan dalam pelayanan, kepedulian terhadap pelanggan, kemudahan dalam pembayaran, keamanan, dan kenyamanan lokasi.

b. Atribut pelayanan yang dinilai dapat memuaskan konsumen Lokal Coffee terdapat 7 atribut yaitu cita rasa, keberagaman menu, kesesuaian produk, kebersihan tempat, keramahan dan kesopanan karyawan, kecepatan dan ketelitian dalam pelayanan, dan ketersediaan toilet.

3. a. Atribut pelayanan yang perlu dipertahankan pada Kopi Ketje terdapat 9 atribut yaitu cita rasa, kesesuaian produk yang diberikan dan ditawarkan, kebersihan tempat, keramahan dan kesopanan karyawan, keadilan dalam pelayanan, kepedulian terhadap pelanggan, kemudahan pembayaran, keamanan, dan kenyamanan lokasi. 
b. Atribut pelayanan yang perlu dipertahankan pada Lokal Coffee terdapat 7 atribut yaitu cita rasa, menu beragam, kesesuaian produk yang diberikan dan ditawarkan, kebersihan tempat, keramahan dan kesopanan karyawan, kecepatan dan ketelitian dalam pelayanan, dan ketersediaan toilet.

c. Atribut pelayanan yang perlu untuk ditingkatkan pada Kopi Ketje terdapat 6 atribut yaitu harga, kecepatan dan ketelitian dalam pelayanan, kemampuan berkomunikasi karyawan kedai kopi, ketersediaan tempat parkir, ketersediaan toilet, dan ketersediaan mushola.

d. Atribut pelayanan yang perlu untuk ditingkatkan pada Lokal Coffee terdapat 6 atribut yaitu harga, ukuran porsi, keadilan dalam pelayanan, kenyamanan lokasi, ketersediaan tempat parkir, dan ketersediaan mushola.

\section{Saran}

Saran yang dapat diberikan berdasarkan hasil analisis pada penelitian ini sebagai berikut.

1. Pihak Kopi Ketje dan Lokal Coffee disarankan untuk mempertahankan atribut yang menjadi keunggulan pada masing-masing kedai kopi agar konsumen tetap merasa puas dan akan mengunjungi kedai kopi kembali.

2. Pihak Kopi Ketje dalam mengatasi beberapa atribut yang dinilai kurang memuaskan, Kopi Ketje dapat melakukan beberapa hal seperti lebih teliti dalam mencatat pesanan dan melakukan konfirmasi pesanan saat konsumen selesai memesan, lebih sigap dan memanajemen waktu, mengadakan pelatihan mengenai cara berkomunikasi yang baik, melengkapi perlengkapan toilet yang kurang seperti cermin dan tisu toilet, dan mengalihkan ruangan yang jarang dipakai menjadi mushola.

3. Pihak Lokal Coffee dalam mengatasi beberapa atribut yang dinilai kurang memuaskan, Lokal Coffee dapat melakukan beberapa hal seperti memberikan nomor antrean dan melayani berdasarkan nomor antrean, mengalihkan fasilitas yang kurang penting dan kurang diperlukan ke fasilitas yang lebih dibutuhkan konsumen, memberikan seragam khas Lokal Coffee kepada karyawan agar meningkatkan penampilan karyawan, dan mengalihkan ruangan 


\section{ANALISIS TINGKAT KEPENTINGAN DAN KINERJA PELAYANAN \\ KEDAI KOPI KETJE DAN LOKAL COFFEE DI KOTA METRO \\ Agus Hudoyo, Tri Tarsita Aprilyano}

yang jarang dipakai menjadi mushola.

4. Sebaiknya pihak Kopi Ketje dan Lokal Coffee mengadakan penilaian secara berkala terhadap kedainya dengan menganalisis kepuasan pelanggannya untuk mengetahui kelebihan dan kekurangan dari kedai kopi agar usaha kedai kopi lebih maju lagi ke depannya.

\section{DAFTAR PUSTAKA}

Arfi, M. (2015). Analisis Strategi Bauran Pemasaran Coffee Shop dengan Metode Importance Performance Analysis (Studi Kasus di Coffee Shop X Di Kota Bandung) [Universitas Katholik Parahyangan]. In Jurnal Polimdo. http://jurnal.polimdo.ac.id/index.ph $\mathrm{p} / \mathrm{ab} / \mathrm{article} / \mathrm{view} / 60 / 55$.

$[15$ Desember 2020]

Azwar, S. (2007). Metode Penelitian. Yogyakarta: Pustaka Pelajar.

Cronbach, L. J. (1951). Coefficient Alpha and Internal Structure of Test. Psychometrika, 16(3), 297-334. http://kttm.hoasen.edu.vn/sites/defa ult/files/2011/12/22cronbach_1951 coefficient_alpha.pdf [6 Maret 2020].

Damanik, P. (2014). Analisis Kepuasan Konsumen Terhadap Kualitas Minuman Kopi dengan Metode Importance Performance Analysis (IPA) dan Customer Satisfaction Index (CSI) (Studi Kasus di Coffee Story Malang) (Skripsi). Fakultas Teknologi Pertanian, Universitas Brawijaya. Malang.

Dinas Perdagangan Kota Metro. (2020). Data Kedai Kopi Di Kota Metro.
Dinas Perdagangan Kota Metro.

Kementerian Pertanian Republik Indonesia. (2019). Buletin Konsumsi Pangan. 10(2). http://epublikasi.pertanian.go.id/ars ip-buletin/53-buletin-

konsumsi/677-buletin-konsumsivol-10-no-2-2019. [8 Februari 2020].

Lieberto, S. (2019). Evaluasi Kinerja Bauran Pemasaran Coffee Shop Brand Internasional dan Lokal (Studi Kasus di Mall Boemi Kedaton) (Skripsi). Jurusan Teknologi Hasil Pertanian, Fakultas Pertanian, Universitas Lampung. Bandar Lampung.

Lubis, S.N., Fauzia, L., \& Utami, D. (2020). CSI (Customer Satisfaction Index) and IPA (Importance Performance Analysis) of Mandheling Coffee in Medan. IOP Conference Series: Earth and Environmental Science, 454, 1-7. https://iopscience.iop.org/article/10. 1088/1755-1315/454/1/012007. [15 Desember 2020].

Meilani, M., Indriani, Y., \& Abidin, Z. (2019). Identifikasi Atribut Pelayanan dan Tingkat Kepuasan Konsumen Rumah Makan Bakso Di Lingkungan Universitas Lampung. Jurnal Ilmu-Ilmu Agribisnis, 7(2), 172-178.

Prasetyowati, A., Hudoyo, A., \& Rangga, K. (2016). Identifikasi atribut kepuasan konsumen dan pelayanan rumah makan olahan ayam di Kota Bandar Lampung. Jurnal Ilmu-Ilmu Agribisnis, 4(4), 384-390. http://jurnal.fp.unila.ac.id/ iindex.php/JIA/issue/view/141. [10 Maret 2020].

Putra, F. C. (2019). Analisis Pengukuran Tingkat Kualitas Pelayanan Terhadap Kepuasan Pelanggan dengan Metode Service Quality (Servqual) yang Diintegrasikan 
dengan Metode Importance Performance Analysis (IPA) (Studi Kasus pada Cafe Kopi Manao Cirebon-Jawa Barat) (Skripsi). Universitas Islam Indonesia. Yogyakarta.

Sugiyono. (2009). Metode Penelitian Kuantitatif dan Kualitatif. Bandung: CV Alfabeta.

Supranto, J. (2006). Pengukuran Tingkat Kepuasan Pelanggan untuk Menaikkan Pangsa Pasar. Jakarta: Rineka Cipta.

Toffin Indonesia. (2020). Toffin Indonesia Merilis Riset "2020 Brewing in Indonesia." https://insight.toffin.id/toffinstories/toffin-indonesia-merilisriset-2020-brewing-in-indonesia/. [5 Januari 2021].
Triani, T. L., Hudoyo, A., \& Suryani, A. (2016). Identifikasi Atribut Kepuasan dan Pelayanan Rumah Makan: Studi Kasus pada Dua Rumah Makan Olahan Bebek Di Kota Bandar Lampung. Jurnal Ilmu-Ilmu Agribisnis, 4(4), 398405.

Warokka, G. F., Pangemanan, S. S., \& G, W. F. (2017). Analisis Atribut Restoran dari Rumah Kopi K8 dan Restoran Di Manado Menggunakan Analisis Kepentingan dan Kinerja. Jurnal EMBA, 5(3), 3435-3442. 